\title{
THE SEMANTIC CONTENT OF PARTIALLY DESCRIPTIVE NAMES*
}

\author{
ZOLTÁN VECSEY
}

\begin{abstract}
According to contemporary Millianism the semantic content of an ordinary proper name is simply its referent. In his recent book Beyond rigidity Scott Soames elaborated a new version of millianism. He claimed that some linguistically complex names such as Professor Saul Kripke or Princeton University have partially descriptive semantic content. In addition to their unique referents, these names are always associated with a special kind of description. I argue in this paper that Soames's theory of partially descriptive names fails, because descriptive contents can be found only in the background knowledge of competent speakers.
\end{abstract}

\section{Introduction}

Defenders of the traditional Millian doctrine often say that the semantic content of an ordinary proper name is simply its referent. According to this popular view a particular nonmetaphorical, nonironical utterance of a declarative sentence $s$ with a proper name $n$ expresses semantically the information that the speaker is primarily concerned to communicate about the referent of $n$. That is to say that in normal everyday contexts proper names contribute to the asserted communicative information exclusively with their referents. In addition, contemporary Millians claim that in such cases the asserted information content of a declarative sentence is a singular or "Russellian" proposition. The most distinctive feature of singular propositions is that they contain objects and persons and their properties as constituents. Accordingly, in (1), the expressed singular proposition contains both the person Kripke and the property of living in Princeton.

\footnotetext{
* The publication of the paper was supported by the Research Group for Theoretical Linguistics of the Hungarian Academy of Sciences at the University of Debrecen.
} 
(1) Saul Kripke lives in Princeton.

The somewhat metaphorical term "contains" means here that relative to the actual world the proposition is in fact about Kripke and the property of living in Princeton. In other words: the proposition attributes a realworld property to a real-world person.

It is of great theoretical importance that in singular propositions the individual constituents are directly represented, without mediation of any further qualities. So in (1) the name Saul Kripke contributes to the expressed proposition only with the person to whom it in fact refers. In this specified sense of semantic content proper names pick out their real-world referents directly and never contain additional qualitative or descriptive informations.

According to a slightly reformulated Millian view, defended recently by Soames (2002) and mentioned in agreement with him by Sullivan (2003), there are however interesting exceptional cases to this rule. Soames (2002) offers a detailed argument to show that certain Millian names have a twofold semantic structure. Although linguistically simple proper names typically do not contain any descriptive information, some complex names such as the phrases Princeton University or Professor Saul Kripke are regularly associated with descriptive properties that apply only contingently to their bearers. Soames introduced the notion partially descriptive names to deal with these complex phrases.

The semantic structure of partially descriptive proper names consists of two separable parts. On the one hand, as ordinary Millian names all such names have in the actual world a unique referent. On the other hand, they are associated with contingent descriptive information. The semantic content of a partially descriptive name includes therefore both a nondescriptive and a descriptive component. The nondescriptive component - the referent of the partially descriptive name $n$-is the historically or causally determined object $o$. This means that the object $o$, which stands at the beginning of a historical or causal chain of transmission of the name $n$, is initially determined by an ostensive baptism or by a descriptional stipulative naming. The descriptive componentthe contingent property $P_{c}$ attached to the object $o$-is specified in every particular case by the referential intentions of speakers, who utter declarative sentences with the name $n$. On Soames's view these two components play a parallel and complementary role in fixing the reference of the partially descriptive name $n$. It is supposed furthermore that the 
descriptive component is of substantial semantic importance, because it has a reference-fixing role in a long-term sense. Once the referent has been fixed, every competent speaker in the future who utters declarative sentences in normal circumstances with the name $n$, will attach the contingent property $P_{c}$ to $o$. Thus $P_{c}$ remains permanently associated with the name as a timeless descriptive reference-fixing definition.

It is clear at first sight that Soames's train of thought results in a hybrid theory, which aims to reconcile essential antidescriptivist and descriptivist insights concerning the semantics of proper names. This procedure is an ambitious research program in itself, surely, but I do not think that Soames's theory in its present form succeeds. In the following brief comment, I will give an argument that purports to show the main flaw in his reasoning.

\section{Competence conditions for partially descriptive names}

Let us first consider what governs our everyday linguistic behavior when we utter simple declarative sentences with ordinary proper names. Because of the great variety of communicative situations where proper names usually occur, and because of the possible diversity of speaker intentions in these situations, the question of the governing principles of everyday usage seems to be extremely complicated, but, fortunately, we can concentrate here on two salient and theoretically significant features of our linguistic practice.

The first obvious thing to say about everyday usage is that if speakers are to speak about an object or person, they must have a discriminating cognitive fix on the thing or person. It is tempting to explain this obvious fact by holding that from the point of view of speakers, the cognitive mechanism of discriminative fixing functions as a background condition of successful communication. Maybe, this discriminative ability can be seen as the necessary cognitive precondition for using words with referential power even in general. If so, then in the case of ordinary proper names this means that to use such names as Princeton or Saul Kripke successfully, speakers must have the corresponding cognitive intentions to discriminate the city and the person to which these names respectively refer.

Beyond discriminative intentions speakers must also have some reflective linguistic capacity to count as competent with the public information content of proper names. The need for this second cognitive condition seems to be equally obvious for the simple reason that in declarative sen- 
tences ordinary proper names stand in general in subject position. There are, of course, relatively often used sentence forms where names occupy other syntactical places. Sometimes personal names may seem to occur predicatively, as, for example, in the sentence This smart guy is Saul Kripke. Names may appear naturally in an isolated position, too. In answering customary interrogative sentences, such as Who is this smart guy?, speakers could use personal names as syntactically unstructured one-word replies. But apart from these clear exceptional cases, in the vast majority of situations where a speaker uses the name $n$ in simple declarative sentences to refer to the object $o$, she uses $n$ in subject position to indicate which thing she is trying to convey information about. There is a schematic empty sentence form $n$ is $F$, which must be filled in every case with a name and a property for the concrete utterance to say something definite. It follows from this that it must be known to speakers at least implicitly what it takes in normal contexts to assertively utter sentence tokens which contain proper names in their subject positions. That is, to be able to say of the referent (the object $o$ ) of $n$ that it has the property F-hood speakers must be equipped with some reflective syntactic knowledge. Consider sentence (1) again:

(1) Saul Kripke lives in Princeton.

(1) expresses the singular proposition that predicates the property of living in Princeton of Kripke. Therefore, speakers must reflectively understand that in all normal contexts by assertive utterances of (1) they are attributing to the referent of Saul Kripke the property of living in Princeton.

With similar considerations in mind, Soames mentions the following two competence conditions for ordinary proper names. ${ }^{1}$

C1. Speakers must possess referential intentions that determine $o$ as the referent of $n$ in normal conversational situations. This communicative intention may arise either from a direct epistemic source (introducing an expression to name the object $o$, on the ground of personal acquaintance with $o$ ) or from an indirect linguistic source (intending to refer to the object $o$ by way of linguistic reference) ${ }^{2}$

\footnotetext{
${ }^{1}$ See Soames $(2002,65)$.

${ }^{2}$ In what follows I will ignore the difference between epistemic and linguistic sources of referential intentions.
}

Acta Linguistica Hungarica 52, 2005 
C2. With respect to a given context, speakers must realise that with assertive utterances in the form $n$ is $F$ they say about the referent of $n$ (about the object $o$ ) that it is $F$.

In my opinion, there is something deeply and indisputably right in the formulation of these two conditions. $\mathbf{C} 1$ mirrors the intuitively right point of the externalist theories of intentionality that successful de re linguistic reference with singular terms requires always individuating mental intentions. C2 invokes the plausible epistemic idea that (implicit) reflective knowledge about the functioning of the sentence scheme $n$ is $F$ counts as a prerequisite for assertively uttering sentences in a given context with ordinary proper names. Reading $\mathbf{C} \mathbf{1}$ and $\mathbf{C 2}$ together as an integral whole, we can see what traditional Millianism says at a fundamental level about competence conditions concerning proper names.

What complicates matters a little bit, however, is the fact that in contrast with ordinary proper names partially descriptive names are syntactically structured linguistic entities. If we are prepared to agree with Soames's original hybrid theory, then we must suppose that these names have also certain competence conditions. Now what would be involved in the competence conditions of partially descriptive names? Soames seems to forget to discuss this important question. ${ }^{3}$ Before I try to fill this gap, consider the following short list of examples:

\section{Grammatical Types of Partially Descriptive Names}
(A) Princeton University, Yankee Stadium.
(B) Whidbey Island, Snoqualmie Falls.
(C) Professor Saul Kripke, Princess Diana.
(D) Miss Ruth Barcan, Mr. Terry Thomas. ${ }^{4}$

Here, in each case a proper name occurs as part of a noun phrase. In (A) and (B) we see ordinary proper names which are followed by common nouns. In $(\mathrm{C})$ the phrases are structured of course in reverse order. ${ }^{5} \mathrm{Be}-$ yond this superficial syntactic remark, the decisive question is, I think, how these different phrasal constituents interact semantically. The an-

\footnotetext{
${ }^{3}$ This is a striking deficiency of his book, because he analyses the behavior of descriptive names in three different chapters.

${ }^{4}$ All examples stem from Soames (2002).

${ }^{5}$ For ease of discussion I abstract here from the somewhat problematic type (D).
} 
swer seems to be perfectly straightforward: the interaction of ordinary proper names and common nouns in noun phrases yields semantic mixtures or semantic amalgams. If partially descriptive names are really genuine proper names, then they contribute to the propositional content of declarative sentences only with their referents. Thus, they are rigid designators in the classical Kripkean sense. In possible worlds similar enough to our actual world the phrase Professor Saul Kripke, for example, always refers to the same person, if it designates anything at all, since the name Saul Kripke is rigid. But, as Soames suggests, partially descriptive names behave, strictly speaking, not rigidly, because the kind of content they semantically express includes also contingent properties of their referents. ${ }^{6}$ That is, in the phrase Professor Saul Kripke the common noun professor is a nonrigid property designator. So there are such counteractual worlds in the modal space where the very person who in our actual world is a professor and bears the name Saul Kripke, has another profession, and for that very reason the whole phrase cannot be classified without further ado as rigid. This modal anomaly arises from the plain semantic fact that beyond its referent the name contains as additional semantic information the contingent property of professorhood. And the observation generalizes smoothly to the grammatical types from (A) to (D): there is a built in information mixture to the semantic profile of the enumerated names consisting in all cases of (i) the rigidly designated particular objects, and (ii) the appropriate contingent properties attached nonrigidly to the designated particular objects. To illustrate the hidden informational structure of these names, Soames gives the following general formula: the $x$ : $D x \& x=y$, where the definite description $D$ represents the contingent property attached to the referent of the name, relative to an assignment of the variable $y$. According to this formula, the structure of the name Professor Saul Kripke must be analysed in the following way: the $x: x$ is a professor $\& x=y$, under an assignment of Saul Kripke to the variable $y .^{7}$

\footnotetext{
${ }^{6}$ See Soames $(2002,120)$.

${ }^{7}$ Soames (op.cit., 110) says in fact that that the semantic contents of partially descriptive names are roughly the same as the semantic contents of certain definite descriptions. It is not entirely clear for me what the adverb roughly means in this context. If partially descriptive names are synonymous with definite descriptions, the synonymy relation between them must hold unambiguously.
} 
If partially descriptive names are structured really this way, it follows that the previously mentioned two competence conditions C1 and C2 must be complemented by $\mathbf{C 3}$, or by something analogous with it.

C3. In using a partially descriptive name $n$ to refer to an object $o$ in normal conversational situations speakers must permanently associate the contingent descriptive property $P_{c}$ with the object $o$.

At this point, we should accept the thesis, for the sake of argument at least, that in our actual world under normal circumstances an average speaker could have cognitive access to the whole semantic content of a partially descriptive name. Then the main question is whether these three conditions C1, C2 and C3 jointly show what speakers in our actual world must know in general to understand and use such names competently. I am sceptical concerning this question, because the condition about associated properties poses in my view an insurmountable problem for Soames's theory. What I would like to do in the remainder of the paper is to demonstrate why such a condition as C3 cannot be met.

\section{Where does descriptive information come from?}

While ordinary proper names represent only their referents, a partially descriptive name, according to Soames, gets into the process of a particular conversation with a referent and an associated descriptive property. Consider what he would say about the following sentence pair, uttered alternatively in a situation where prior to the time of the concrete utterance both the speaker and the hearer were competent users of the linguistically simple names Saul Kripke and Princeton (i.e., they satisfy in advance the requirements of $\mathbf{C} \mathbf{1}$ and $\mathbf{C 2}$ ):

(1) Saul Kripke lives in Princeton.

(2) Professor Saul Kripke lives in Princeton.

As for the first sentence, Soames might insist that uttering these words with declarative intentions a speaker conveys no more content semantically than the information that the well-known philosopher of language Saul Kripke lives in Princeton. This seems to be intuitively very plausible because the sentence contains no overtly indexical expressions or other 
context-sensitive grammatical elements with varying referents from context to context and the contextual value of the present tense of the verb counts in normal conversational settings as unambiguous, and because we supposed further that the speaker knew that the hearer has both names in her mental lexicon. ${ }^{8}$

It is quite another matter that in special cases an utterance of (1) could convey possibly more information than just the lean and seemingly trivial proposition that Saul Kripke lives in Princeton. Agents who know various significant things about the life story and personality of Saul Kripke could perhaps know that he does not particularly like the city Princeton. They could know, perhaps from personal communication, that Kripke believes that Princeton is not pretty. In this hypothetical case, an utterance of (1) would imply the descriptive information content to the addressees that because he now lives there, Kripke probably changed his negative opinion about Princeton. This putative descriptive information would belong, however, to the inferential mechanisms employed in the interpretation of the sentence. According to Soames, who distinguishes sharply first-order semantic content from other types of asserted or implicated information, statements with ordinary proper names may carry occasionally some descriptive information which goes beyond the literal meaning of the uttered sentence token. No doubt, sometimes it is an extremely demanding interpretive exercise to determine precisely what this extra information content consists of. Soames acknowledges this, but it is important to see, he says, that this kind of information could be conveyed solely by second-order pragmatic means. ${ }^{9}$

The best candidate for being the semantic content encoded by assertive utterances of (1) is thus the mere information that Saul Kripke lives in Princeton. This is in agreement with other contemporary Millians like Salmon (1986) and Thau (2002) who would presumably maintain that in this sentence, under normal circumstances, the linguistically simple proper name Saul Kripke (and Princeton) lacks any descriptive content.

But what about our second sentence? As C3 suggested above, to count as competent with the partially descriptive name Professor Saul Kripke speakers must permanently associate with the referent of the simple proper name Saul Kripke (i.e., with the person the name rigidly designates) the contingent property of professorhood. From this it follows

\footnotetext{
${ }^{8}$ For detailed arguments see Soames (2002, 63-5).

${ }^{9}$ Soames (op.cit., 86). For a similar view, see Capellen-Lepore (2004).
} 
that in our hypothetical situation, where both the speaker and the hearer are competent users of the simple name Saul Kripke (and Princeton)via satisfying the conditions $\mathbf{C} \mathbf{1}$ and $\mathbf{C 2}$ - an assertive utterance of (2), in contrast to (1), would express the descriptively enriched semantic content that the well-known philosopher of language Saul Kripke, the professor, lives in Princeton. Thus, Soames would conclude that in this case the putative descriptive information is carried by the common noun professor.

\section{Descriptive contents in mental files}

It seems to me that the aforementioned Soamesian inference cannot be justified. The decisive reason for this is that the descriptive content of the property designator professor does not enter necessarily into the asserted content of (2). I think that being a competent user of the proper name Saul Kripke in the actual world at a time $t$ amounts to knowing, among other things, that the designated person is a professor. ${ }^{10}$

On what grounds can one accept this claim? From a cognitive point of view, it can be argued that to count as competent with the name Saul Kripke a speaker must have a separate mental file about the person Kripke. ${ }^{11}$ Let us call it the Saul Kripke File. Beyond some mental pictures, memory-traces of moods and other types of stored information, the Saul Kripke File will be filled very likely with a great amount of contingent semantic information. According to the cognitive hypothesis all contingent semantic content in the Saul Kripke File will be associated with the name Saul Kripke. For competent users, for example, the sound of the words Saul Kripke provides access to all semantic information stored at the moment about Kripke. In this way, speakers may associate with the name such descriptive contents as he is smart, he has a beard,

${ }^{10}$ Recall what condition $\mathbf{C} 1$ says: competent users of a proper name must possess discriminating abilities, that is, they must gain enough knowledge from epistemic or linguistic sources to pick out the designated object determinately. It is easy to imagine contexts in which the deferential source of such a name as Kripke includes regularly a contingent but characteristic feature of the referent. In science classroom contexts, for example, the first encounter with the name may bring about in students a latent association between the person who is called Kripke and the contingent property of professorhood. Kroon would say that this property becomes "resiliently" associated with the name. See Kroon $(2004,282)$.

${ }^{11}$ About mental files see among others Recanati (1993), Geirsson (2001) and Segal (2001). 
he is a professor, and so on (if they have placed these linguistic items previously into their mental files). That is, the associated descriptive contents help them cognitively track the individual named.

This does not mean, of course, that the name contains in its semantic profile these contingent pieces of information. But when competent speakers assertively utter sentences in a public language with the proper name Saul Kripke, they can lean on this previously acquired background knowledge. In successful cases, a coordinated mental file management takes place. Thus, the already known properties of the designated person become part of the common ground among the participants in the conversation. If that is right, then the contingent fact or information that Saul Kripke is a professor must not be explicitly expressed by normal utterances of (2). I conclude, therefore, that for competent hearers (2) expresses the same basic proposition semantically as (1), namely that Saul Kripke lives in Princeton. To take one more example, consider the following sentence pair (3) and (4).

(3) Peter Hempel was Carl Hempel. ${ }^{12}$

(4) Professor Peter Hempel was Professor Carl Hempel.

Here it is even clearer that there could not be a significant difference between the expressed semantic content of the two sentences. I agree entirely with Soames's claims about the possible utterance contents of (3). It is very likely that an average speaker could use (3) to communicate different things in different contextual settings. One could assert with (3) the contextually enriched identity statement, for example, that the man formerly known by the name Peter Hempel was in fact identical with the famous philosopher of science Carl Hempel. On another occasion the sentence might convey the metalinguistic proposition that there was only one famous philosopher named Hempel, and perhaps there are a few other real possibilities. According to Soames, however, (3) expresses semantically no more than the simple fact that the rigidly designated objects of the two proper names Peter Hempel and Carl Hempel are identical. And it is easy to see that the first-order content of this identity relation does not contain any descriptive information. So far so good.

One problem now arising, though, is that contrary to the explicit expectations of Soames's theory (4) seems to express semantically the

\footnotetext{
${ }^{12}$ For a detailed analysis of (3), see Soames $(2002,66)$.
} 
very same content. If our hypothetical speaker has the required minimal background knowledge to be a competent user of (4) - that is, she has a suitable mental file about the person Hempel - she may know, among other things, that Peter Hempel was at a given time $t$ professor, and she may also know that he was in fact identical with Carl Hempel. Therefore, the common noun component professor of the partially descriptive names Professor Peter Hempel and Professor Carl Hempel will stay, we could say, in an inert position in her everyday utterances of (4). It changes the ordinary proper names Peter Hempel and Carl Hempel into syntactically complex names, but does not provide them with new and significant descriptive semantic power. This semantic inertness of the property designator professor shows, in my view, that regarding first-order content there is no significant difference between (1) and (2), and similarly, (3) and (4) do not differ in their expressed semantic content.

So it seems that Soames's general formula the $x: D x \& x=y$ does not represent accurately the hidden informational structure of these names, when $D$ is interpreted semantically. This formula should be reinterpreted in a way which fits better with the cognitive competence conditions mentioned above.

\section{Conclusion}

As we saw before, there are good reasons for Soames and other contemporary Millians to accept C3. They are entitled to say that partially descriptive names must express semantically contingent properties of their designated objects across normal contexts involving competent speakers. We also saw, however, that prior to using such names in declarative sentences competently speakers must possess some discriminating background knowledge about their designated objects. This is why I doubt that there is a direct way to meet condition C3.

It seems likely therefore that the main thesis of Soames's attractive theory fails, and partially descriptive names lack semantically valuable descriptive information; perhaps they are not names at all. ${ }^{13}$ At the same time, I am convinced that this failure does not threaten Soamesian Millianism about ordinary proper names. The above-mentioned two conditions $\mathbf{C} 1$ and $\mathbf{C 2}$ provide the strongest evidence why this is so. We may also reject the inherently unstable idea of partially descriptive names and yet still hang on to traditional Millianism in the case of ordinary names.

${ }^{13}$ McKinsey (2004) argues similarly. He claims that Soames has produced no real examples of partially descriptive names.

Acta Linguistica Hungarica 52, 2005 


\section{References}

Cappelen, Herman - Ernie Lepore 2004. Insensitive semantics. Blackwell, Malden MA \& Oxford.

Geirsson, Heimir 2001. Discovering identity. In: Southwest Philosophy Review 17 : $43-57$.

Kroon, Frederick 2004. A-intensions and communication. In: Philosophical Studies $118: 279-98$.

McKinsey, Michael 2004. Remarks on Scott Soames's Beyond Rigidity. Paper presented at the meeting of the Pacific APA Division, Pasadena.

Recanati, François 1993. Direct reference: From language to thought. Blackwell, Cambridge MA \& Oxford.

Salmon, Nathan 1986. Frege's puzzle. MIT Press, Cambridge MA.

Segal, Gabriel 2001. Two theories of names. In: Mind \& Language 16 : 547-63.

Soames, Scott 2002. Beyond rigidity: The unfinished semantic agenda of naming and necessity. Oxford University Press, Oxford.

Sullivan, Arthur 2003. Beyond rigidity. In: Philosophical Books 44:317-34.

Thau, Michael 2002. Consciousness and cognition. Oxford University Press, Oxford.

Address of the author: Zoltán Vecsey

Institute of Germanistics

University of Szeged

Egyetem utca 2.

H-6722 Szeged

Hungary

vecseyz@freemail.hu

Acta Linguistica Hungarica 52, 2005 